\title{
A vida de Lima Barreto, de Francisco de Assis Barbosa e Lima Barreto: triste visionário, de Lilia Moritz Schwarcz
}

Marcos Vinícius Scheffel

Professor de Didática e Prática de Ensino de Português e Literatura da UFRJ;

E-mail: marcos.scheffel53@gmail.com

\section{Resenha dos livros:}

BARBOSA, Francisco de Assis. A vida de Lima Barreto. $11^{\mathrm{a}}$ ed. São Paulo; Rio de Janeiro; Belo Horizonte: Autêntica Editora, 2017. 432 p.

SCHWARCZ, Lilia Moritz. Lima Barreto - triste visionário. São Paulo; Rio de Janeiro: Companhia das Letras, 2018. 648 p.

A Festa Literária de Paraty, em sua décima quinta edição realizada em julho de 2017, ao homenagear Lima Barreto, promoveu uma retomada da obra do autor fluminense. É certo que se trata de um autor incorporado ao cânone das letras brasileiras e que seus livros vêm sendo procurados por gerações de leitores, admiradores e críticos, que identificam em sua escrita um viés de crítica social, de denúncia aos preconceitos e de desapontamento com os primeiros anos de nossa república. Também é certo que sua trajetória pessoal marcada pelo preconceito racial, pela loucura e pelo alcoolismo ajudaram na construção de todo um imaginário que fez, muitas vezes, sua escrita ficar num segundo plano ou ser considerada apenas como uma tentativa de ficcionalizar essas vivências a partir de um ponto de vista "marginalizado" e "suburbano". Isto tudo aparecendo em estudos acadêmicos (teses, dissertações, artigos), em textos jornalísticos e em manuais escolares.

Estes aspectos mais evidentes foram explorados tanto pelos organizadores da Festa Literária de Paraty como pelo mercado editorial, que teve entre suas principais novidades duas biografias do autor. A primeira delas é a $11^{\mathrm{a}}$ edição de $A$ vida de Lima Barreto, de Francisco de Assis Barbosa, que fora 
publicada pela primeira vez em 1952; a segunda, Lima Barreto: triste visionário (2017), assinada pela antropóloga Lilia Moritz Schwarcs, foi o livro mais esperado neste ano de homenagens e sua organizadora esteve na mesa de abertura da FLIP ao lado do ator Lázaro Ramos que leu trechos da referida obra. Um contraste entre essas duas biografias parece bastante relevante dado o lapso temporal de 65 anos que as separa e as diferentes propostas de cada uma delas.

Sobre o trabalho de Francisco de Assis Barbosa pode-se dizer que ele está diretamente relacionado à redescoberta de Lima Barreto no final dos anos 40 e início da década de 50. Foi nesse período que ele conheceu Evangelina de Lima Barreto, que lhe confiou os manuscritos do irmão dela. A partir desse momento Francisco de Assis Barbosa nunca mais abandonou a obra de Lima Barreto, até sua morte em 1991. Ele esteve à frente da preparação das obras completas pela Brasilense - 17 volumes com prefácios dos principais críticos da época - e travou um contato direto, corporal, com um arquivo composto por crônicas, cartas, contos, romances (completos e inacabados) e muitas anotações feitas pelo autor em cadernetas e folhas avulsas que se transformaram no Diário Íntimo, que põe lado a lado anotações pessoais e projetos ficcionais do autor.

Este corpo a corpo com a escrita de Lima Barreto - inclusive com os manuscritos de difícil decifração - forneceu ao biógrafo matéria de sobra para escrever uma biografia sobre Lima Barreto e deixou um caminho aberto para pesquisas futuras. Além destes materiais, disponibilizados pela irmã do autor, ele contou ainda com a proximidade temporal, pois Lima Barreto tinha falecido precocemente aos 41 anos de idade em 1922 e muitos dos seus contemporâneos (afetos e desafetos, críticos e admiradores) ainda estavam vivos e puderam contar histórias sobre o biografado.

Tendo acesso a todo esse material, Francisco de Assis Barbosa, que demorou cinco anos para escrever A vida de Lima Barreto, tinha ainda um grande desafio: organizar tudo isso de forma a fornecer aos seus contemporâneos uma imagem de Lima Barreto que pudesse reinseri-lo nas letras nacionais. Vale lembrar que da morte do autor até os anos 1950 muita coisa aconteceu na literatura brasileira. A década de 30, por exemplo, fora marcada por um verdadeiro boom de escritores que de norte a sul do Brasil produziram uma literatura preo- 
ANDRADE, Mário de. Aspectos da literatura brasileira. 6 ed. São Paulo: Livraria Martins Editora S.A.; 1978. P.90108. Destaco aqui que a meu ver as opiniões de Mário de Andrade devem ser vistas com cuidado, pois elas parecem uma provocação e uma tentativa de afirmação geracional (no caso da geração modernista de 1922). Prova disso é que neste artigo e desqualifica o contista Machado de Assis e tempos depois instado a escolher os dez melhores contos brasileiros diz que não eram dez mas vinte, pois os dez primeiros eram de Machado.

2 Esta $11^{\mathrm{a}}$ edição traz os prefácios das edições anteriores e um breve texto de Beatriz Resende falando sobre o biógrafo. cupada com questões sociais: a seca, o latifúndio, o atraso do interior do Brasil, a herança escravagista, os menores de rua, a precarização da vida nas grandes cidades etc. O caráter social da obra literária tornou-se naquele momento um aspecto extremamente valorizado e serviu como régua para medir tanto autores contemporâneos como autores do passado - bastando lembrar os juízos negativos que Mário de Andrade fez sobre a obra de Machado de Assis, tachado de "antimulato" e de "antiproletário" e visto como um escritor que para vencer nas letras teve que ocultar muito de si (não falar de suas origens raciais) e escrever numa língua altamente estetizada. ${ }^{1}$

Nesse ponto, pode-se pensar que seria muito produtivo o surgimento de um escritor que fosse por assim dizer o antípoda de Machado de Assis, ou seja, que não ocultasse sua origem, que escrevesse a partir de um ponto de vista mulato e proletário / periférico, que tirasse o foco do estético e centrasse sua atenção no social e que escrevesse muito sobre si. Aliás, sob esse último aspecto, Francisco de Assis Barbosa toma-o como elemento estruturante de sua biografia, pois como se pode ler no prefácio da primeira, edição Lima Barreto pertencia "à categoria dos escritores que mais se confessam através de sua obra" (p.23)2. Desta forma, em vários pontos, o biógrafo se vale da escrita ficcional de Lima Barreto para entender os sentimentos, as angústias, os posicionamentos ideológicos, as preferências literárias etc. O criador tem semelhanças com algumas de suas personagens. São semelhanças físicas - caso dos personagens mulatos, negros e mestiços; semelhanças profissionais: escritores, funcionários públicos; semelhanças sociais: muitos deles habitantes dos subúrbios; Esta estratégia de recorrer ao ficcional para entender o autor também serve para descrever a posição de Lima Barreto no campo literário / social do início do século XX e sua ideologia a partir das críticas que tece a determinados grupos ou indivíduos.

Fora isso, tais comparações servem ainda para preencher lacunas da vida do autor, por exemplo, a atuação de João Henriques como almoxarife na Ilha do Governador (para descrever o pai de Lima Barreto o biógrafo compara-o ao personagem Policarpo Quaresma por conta do envolvimento de ambos com a agricultura). Deve-se destacar que sempre o biógrafo se vale de recursos de modalização quando promove 
3 Ao longo das décadas que se sucederam diferentes facetas de Lima Barreto foram surgindo em estudos como os de Antonio Arnoni Prado, Beatriz Resende, Luciana Hidalgo, Carmem L. Negreiros de Figueiredo ou na admiração que o autor gerou entre outros autores como João Antônio, Carlos Drummond de Andrade e Osman Lins. tais comparações, numa escala que vai da leve semelhança, passa por pontos de contato e chega à semelhança total entre o biografado e suas personagens.

Toda essa malha intrincada está a serviço de uma escrita fluida e que consegue gerar um forte sentimento de simpatia por Lima Barreto, que aparece aos nossos olhos como a figura de um Quixote, lutando contra tudo e contra todos para cumprir seu principal objetivo: tornar-se reconhecido pela sua escrita. São grandes os objetivos que Lima Barreto teria construído para si e as dificuldades que encontrou para realizá-los explicariam a amargura que tomou conta dos últimos anos de vida do autor, levando-o ao alcoolismo e a sucessivas internações. Apesar desses traços dramáticos da vida de Lima Barreto, o que salta aos olhos do leitor desta biografia é o intelectual e o escritor. Mesmo em passagens melancólicas, como a da internação psiquiátrica, o que se vê é um Lima Barreto que levanta, sacode a poeira e dá a volta por cima e sempre de olho na literatura. São trechos de uma alta carga lírica e que mostram que o Francisco de Assis Barbosa superava em muito "o repórter que tem feito do jornalismo literário o seu ganha-pão" (p.23).

Habilidosamente, Francisco de Assis Barbosa consegue focalizar as leituras, as amizades no campo intelectual e apresenta ao final do volume um importante documento: a biblioteca de Lima Barreto - catalogada e organizada pelo autor de Policarpo Quaresma. Ali está a vida do autor, os livros e revistas preferidos (em vários idiomas), recortes de jornal criteriosamente organizados (muitos deles com apontamentos feitos a mão) e originais de livros seus publicados ou por publicar. Sem objetivos de fazer crítica literária, como bem destaca no prefácio da primeira edição, Francisco de Assis Barbosa abriu caminhos importantes para as futuras gerações de críticos que se deparavam com fortes indícios da complexidade da escrita barretiana ${ }^{3}$.

Dito isso, percebe-se que estamos diante de uma das mais belas biografias escritas em língua portuguesa sobre um escritor. O livro de Francisco de Assis Barbosa torna-se uma espécie de obstáculo quase intransponível para aqueles que querem escrever sobre aspectos biográficos de Lima Barreto. Algumas questões se imporiam a quem se arvorasse a escrever uma nova biografia. O primeiro deles seria reconhecer que 
muito do que estava escrito ali no livro de Francisco Assis Barbosa estava a serviço de preencher vazios que os documentos em si não supriam e que partiam do pressuposto que o autor confessava demais em sua ficção. Assim, as comparações entre personagens e momentos da vida do autor não deveriam ser tomados como documento.

Nesse sentido, é estranho que Lima Barreto: triste visionário não tenha tomado esse cuidado e tenha repetido de maneira sistemática e repetida muitas das comparações feitas por Francisco de Assis Barbosa: Policarpo Quaresma e João Henriques, Lima Barreto e Isaías Caminha, personagens de contos e a trajetória do autor. Fora a repetição do mecanismo, parece que a ideia de que Lima Barreto apenas confessava em sua obra foi tomada como uma verdade que poderia ser utilizada e outras comparações foram incorporadas ao tecido narrativo, por exemplo, a comparação entre o autor e sua personagem Gonzaga de Sá.

Diga-se de passagem, essa comparação já ocorria em $A$ vida de Lima Barreto, marcando semelhanças mais gerais entre Lima e Gonzaga: a mania deambulatória, os referenciais literários e históricos e, principalmente, o profundo amor pela cidade do Rio de Janeiro. Em termos sociais, Barbosa prefere comparar Lima Barreto ao personagem narrador Augusto Machado, pois ambos têm a mesma origem racial, são funcionários públicos e partilham de referenciais literários em comum. Já na biografia assinada por Lili M. Schwarcz é justamente ao falar deste romance que os maiores equívocos de interpretação literária são promovidos, pois em vários momentos os pensamentos do personagem-narrador Augusto Machado são atribuídos a Gonzaga de Sá (que dentro da ideia confessional seria um álter ego de Lima Barreto). Fora isso, promove-se uma confusão entre obras que pode passar despercebida a um leitor que não seja especialista em Lima Barreto. Um parágrafo da biografia pode ilustrar algumas dessas questões:

“Lima Barreto, porém, sempre que podia, dava um jeito de se reinventar a partir de seus personagens. Dessa maneira, Policarpo Quaresma é espelhado em seu pai, Isaías Caminha simboliza o preconceito que Lima sentiu na pele quando estudante e nos primeiros tempos de jornalista; já Gonzaga de Sá representa a vida dele como funcionário público. No retrato detalhado que faz da sua atividade como amanuense, no conto 'Três gênios da secretaria', publicado em 1919, o 
4 BARRETO, Lima. Vida e Morte de M.J. Gonzaga de Sá. Cotia/SP: Ateliê, 2017. Edição crítica e anotada que preparei com o professor José de Paula Ramos Jr.

5 Podem-se detectar ainda erros interpretativos sobre Recordações do Escrivão Isaías Caminha (ao dizer que o personagem é morador dos subúrbios do Rio de Janeiro, p. 235), no conto Um e outro (ao afirmar que a personagem Lola é casada com Freitas, p.297 - quando está é tida e mantida por Freitas que é casado com outra mulher) e também um erro ao citar o conto Pai contra mãe, de Machado de Assis. Neste caso, é dito que Cândido Neves "conseguiu 'libertar' seu próprio filho, que se encontrava na Roda dos Enjeitados." (p.328) Isto não ocorreu, pois Cândido Neves deixara seu filho em uma Botica para correr atrás de Arminda - a escrava fugida que procurava há um bom tempo. Também gera confusão um trecho na página 218 sobre Isaías Caminha, pois, ao comparar personagem e autor, ficar parecendo que a mãe da personagem seria professora quando quem era professora era a mãe de Lima Barreto. Há ainda erros de revisão como no título da crônica "Uma fita acadêmica" (aparece na edição "fatia", p.329) escritor a define sem dó nem piedade, mas com muita graça. O trabalho estaria resumido na função desempenhada pela ironicamente denominada Secretaria dos Cultos, que equivaleria à 'sua' Secretaria da Guerra. O texto começa com uma nota dedicada a Augusto Machado, personagem ficcional ao qual Lima atribui a autoria do livro Vida e morte de M.J. Gonzaga de Sá. Nela, o escritor destila ironia em relação à profissão que desempenharia por catorze longos anos: “Logo no primeiro dia em que funcionei na secretaria, senti bem que todos nós nascemos para empregado público. Foi a reflexão que fiz ao me julgar tão em mim, quando, após a posse e o compromisso ou juramento, sentei-me perfeitamente à vontade na mesa que me determinaram. [...] Eu tinha vinte e um para vinte e dois anos; e nela me abanquei como de há muito já o fizesse. Tão depressa foi a minha adaptação que me julguei nascido para ofício de auxiliar o Estado, com a minha reduzida gramática e o meu péssimo cursivo, na sua missão de regular a marcha e a atividade da nação."' (SCHWARCZ 2017, p.146)

No parágrafo acima, além da confirmação da estratégia de correlacionar vida e obra de maneira direta, percebe-se ainda uma tentativa de criar equivalências que não se confirmam na obra. Será mesmo que a Secretaria de Cultos é a Secretária de Guerra? Não é estranho que Gonzaga de Sá trabalhe diretamente com o Barão do Rio Branco como se pode ler no capítulo VI do romance intitulado O Barão, as costureiras e Outras coisas ${ }^{4}$. No trecho sublinhado, ocorre um grave erro que deve ser corrigido em futuras edições, pois do jeito que está escrito parece que a citação foi extraída da "Explicação Necessária", assinada pelo personagem narrador Augusto Machado, que abre o livro, quando temos na verdade um trecho da crônica "Três gênios da secretaria" ${ }^{\prime \prime}$. Ainda sobre este romance há uma insistência em dizer que o romance já estava pronto há mais de dez anos:

"Já sabemos que o original ficara guardado numa prateleira da Limana por muito tempo. A primeira versão do livro datava da época de Recordações e, em 1918, ganhara apenas um novo prefácio. Mesmo sem ter mexido muito no texto, o escritor costumava gabar-se desse romance." (SCHWARCZ 2017, p.383)

"Afinal, a história sobre o amanunense andarilho estava pronta desde os idos de 1909, época do lançamento de Recordações do Escrivão Isaías Caminha." (SCHWARCZ 2017, p.465)

"[...] paradoxalmente uma das primeiras obras escritas mas a última a ser publicada" (SCHWARCZ 2017, p.480) 
Quanto a esse ponto, parece mais sensata a afirmação de Francisco de Assis Barbosa sobre as reformulações que o romance deve ter recebido, lembrando que os originais enviados para Monteiro Lobato se extraviaram e sobraram apenas alguns apontamentos do romance feitos pelo autor no início do século e que demonstram que várias questões mudaram no projeto inicial do livro: o título, o parentesco de Gonzaga de Sá com Escolástica (irmã no projeto inicial e tia no romance), o sobrenome Bragança que é retirado do personagem, as críticas ao romance Canaã, de Graça Aranha etc.

Outra questão que merece ser revista concerne à ideia que Lima Barreto enviou Vida e Morte de M.J. Gonzaga de Sá a seu amigo Noronha Santos para revisá-lo e depois oferecê-lo a Revista do Brasil que era dirigida por Monteiro Lobato (SCHWARCZ 2017, p.377). A cronologia correta dos fatos é a seguinte: Lima Barreto envia os originais de Gonzaga de Sá a Antônio Noronha Santos, em 16 de abril de 1918, para que este faça uma leitura dos originais para enviar para gente do Marinho $^{6}$ - referência a Irineu Marinho proprietário do jornal A noite. Ou seja: Lima Barreto imaginava que o jornal poderia se interessar em publicar o romance em forma de folhetim. Quanto à Revista do Brasil, é Monteiro Lobato quem convida o autor fluminense, em carta de 2 de setembro de 1918, a enviar algo para revista que "deseja ardentemente vê-lo entre os seus colaboradores". A breve carta de Lobato demonstra a admiração pelo autor de Triste Fim de Policarpo Quaresma em especial pelo seu jeito de escrever "sem nenhuma dessas preocupaçõezinhas de toillete gramatical que inutiliza metade de nossos autores."7

Em relação à linguagem utilizada por Lima Barreto, a biografia em questão reitera em vários momentos a ideia que o autor escrevia mal. Hoje, não tem cabimento colocar Lima Barreto como um escritor desleixado e pouco preocupado com questões estéticas. Em outro momento, a comparação pode ter sido útil e produtiva para reinseri-lo no cânone, porém é sabi-

6 BARRETO, Lima. Correspondência Ativa e Passiva $-1^{\circ}$ tomo. São Paulo: Brasiliense, 1956, p. 109.

7 LOBATO, Monteiro. In: Correspondência Ativa e Passiva - $2^{\circ}$ tomo. São Paulo: Brasiliense, 1956, p. 49 do que na verdade o autor fluminense estava escrevendo na norma culta brasileira enquanto seus contemporâneos estavam escrevendo numa norma padrão e presos a uma concepção beletrista do idioma, que desconsiderava as particularidades do português brasileiro. Lima Barreto só pode ser visto como alguém que escreve mal se tomarmos como referência uma 
8 Trata-se da edição crítica e genética preparada por Ceila Maria Ferreira (UFF) e por Carmem Lúcia Negreiros de Figueiredo (UERJ) e com a participação das pesquisadoras Marina Brito de Mello, Patrícia Teixeira e Viviane Arena Figueiredo. Neste trabalho, publicado em 2017 pela editora da USP, há uma comparação entre a última edição de Recordações do Escrivão Isaías Caminha (1917), revista pelo autor, a edição de 1909, os capítulos publicados na Revista Floreal e os manuscritos do autor. A principal conclusão deste estudo: Lima Barreto se preocupava com aspectos formais de sua obra. concepção preciosista da linguagem - aquela concepção de língua que seria duramente fustigada pelos modernistas de 22! Na verdade, ele foi um dos responsáveis pelo combate veemente à língua como monopólio de um pequeno grupo. A língua de Lima Barreto é a nossa língua de hoje, aberta, renovada, democrática (e vez ou outra questionada por um gramatiqueiro de plantão, um herdeiro de Lobo Neves, personagem de Recordações do Escrivão Isaías Caminha).

Outros dois juízos sobre obras que parecem equivocados se referem ao Recordações do Escrivão Isaías Caminha - livro que precisaria "de uma bula para ser lido" - e Triste Fim de Policarpo Quaresma que é classificado da mesma forma que o primeiro, como um romance à clé - um romance em que as personagens são caricaturas facilmente identificáveis por se referirem a figuras públicas conhecidas (bastando saber a chave de leitura, ou seja, quem é o personagem na vida real). Quanto à primeira afirmação, sobre a necessidade de sabermos o nome das pessoas retratadas por Isaías Caminha, ela parece não se sustentar, pois parece bastante atual um romance que crítica: a imprensa - vista com o $4^{\circ}$ poder; os intelectuais - criticados por estarem argolados com o poder e criarem um espaço de autorreconhecimento e exclusão; o racismo vigente na sociedade brasileira e vivenciado por Isaías Caminha. Fora isso, a obra em questão apresenta uma estrutura complexa que não foi entendida em sua época, como destaca a crítica Carmem Lúcia Negreiros de Figueiredo, em estudo que abre uma edição crítica deste romance ${ }^{8}$ :

"Recordações do Escrivão Isaías Caminha move-se por meio do recurso da narrativa em primeira pessoa e do discurso memorialístico, que simula a autobiografia, em um duplo processo. De um lado, a formação do jovem intelectual, em um diálogo com toda a tradição relativa aos efeitos da leitura, do saber da ilustração. De outro, a reflexão, via a relembrança, em busca do autoconhecimento que revela a ausência de sentido e finalidade avessa a tais princípios. $O$ resultado produz um movimento de profunda ironia entre a forma enunciada (memórias de formação intelectual e humanística) e o conteúdo em desenvolvimento, cuja consequência é a contaminação do épico pela reflexão, o esvaziamento da ação narrativa e um herói reflexivo, que vagueia pelas ruas, pelas redações de jornais e em torno de si." (p.17) 
Ao reiterar leituras do passado, que procuravam desqualificar a obra de Lima Barreto, a presente biografia presta um desserviço a um longo processo de ressignificação do autor nas letras nacionais promovido por gerações de críticos. Quanto ao Triste Fim de Policarpo Quaresma, este desserviço é maior ainda ao colocar o livro num lugar que ele nunca esteve, pois mesmo aqueles que desqualificavam Lima Barreto por outras obras sempre indicavam que este romance era diferente dos demais pela ausência de personalismo. Isso demonstra que a biógrafa não só se valeu do mote da primeira biografia - Lima Barreto é um dos autores que mais confessa - como o transformou do seguinte modo: Lima Barreto só confessa em sua literatura.

\section{REFERÊNCIAS}

BARBOSA, Francisco de Assis. A vida de Lima Barreto. $11^{\mathrm{a}}$ ed. São Paulo ; Rio de Janeiro; Belo Horizonte: Autêntica Editora, 2017. $432 \mathrm{p}$.

SCHWARCZ, Lilia Moritz. Lima Barreto - triste visionário. São Paulo ; Rio de Janeiro: Companhia das Letras, 2018. 648 p. 